\title{
Prática e poder simbólico em Bourdieu: a visão de Berkeley
}

Lö̈c Wacquant ${ }^{1}$ Aksu Akçaoğlu ${ }^{2}$

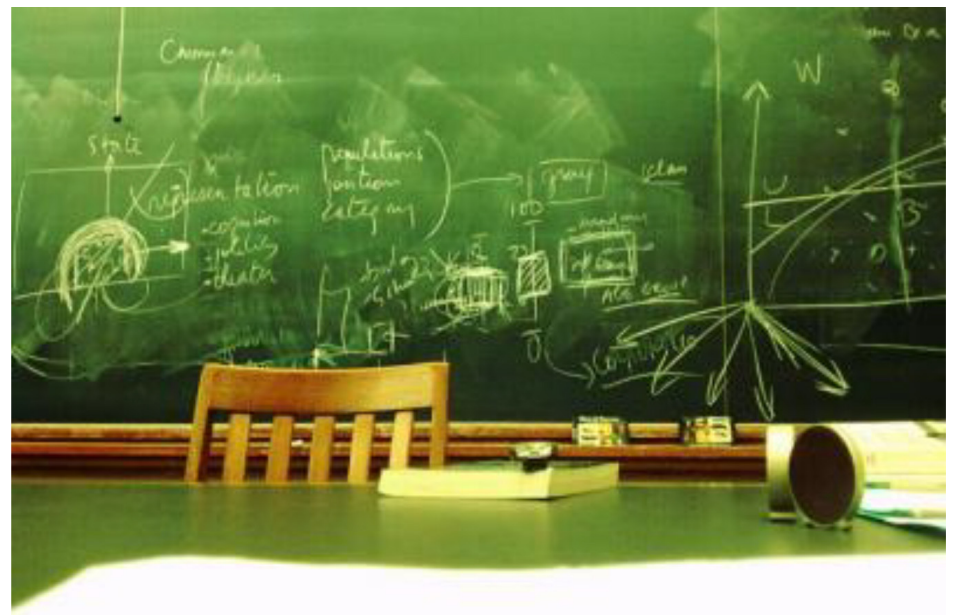

Aksu Akçaoğlu: O tema do "Acampamento Bourdieu" deste ano em Berkeley foi "Prática e Poder Simbólico em Bourdieu". Por que você escolheu esse tema?

Loïc Wacquant: Esse é o título genérico para o SOC202B, um seminário semanal em teoria social avançada, ao qual meus alunos afetuosamente atribuíram apelido militar por causa da intensidade incomum de trabalho que ele requer. Trata-se de um programa de imersão acelerado, no qual você tem que engolir, mastigar e digerir grandes volumes de escritos de Bourdieu, organizados cronológica e tematicamente, cobrindo toda a sua carreira. Trata-se, em essência, de fazer o trabalho de 15 anos de estudo metódico em um curto período de 15 semanas. Quando você se inscreve no seminário, compromete-se a ler, escrever, comer, beber, dormir, sonhar, conversar e pensar Bourdieu 24 horas por dia, durante quatro meses. Para apreender o modus operandi mental distintivo de qualquer grande pensador - seja Bourdieu, Hannah Arendt ou Ibn Khaldun - você deve se enredar profundamente em sua teia intelectual e passar da familiaridade para a obsessão e desta

1 Tradução de Sergio Lamarão. Revisão técnica de Marcia Consolim e Virgílio Borges Pereira.

2 Professor de Sociologia na Universidade da Califórnia, Berkeley, e pesquisador do Centro de Sociologia Europeia, Paris. Seus interesses incluem marginalidade urbana, penalidade, carnalidade e teoria social. Ganhador da MacArthur Prize Fellowship, seus livros foram traduzidos em cerca de 20 idiomas e incluem Corpo e alma: notas etnográficas de um aprendiz de box (edição brasileira lançada em 2002; título original: Body and soul: notebooks of an apprentice boxer, com nova edição ampliada lançada em 2017), Deadly symbiosis: race and the rise of the penal State (2017) e The two faces of the ghetto (2017). Para mais informaçóes, consulte <loicwacquant.net>.

3 Assistente de pesquisa e doutorando no Departamento de Sociologia da Universidade Técnica do Oriente Médio, Ancara. Seus interesses incluem espaço urbano e consumo, diferenciação social e poder, política conservadora e teoria social. Sua pesquisa de doutorado é The conservative habitus: the quest for a new social space in contemporary Turkey. 
para a fusão e vice-versa. Isso implica certo nível de devoção deliberada que esse seminário deve assegurar. O objetivo não é converter o aluno (a teoria social não é teologia), mas torná-lo familiarizado com um modo particular de pensar, do qual você pode se apropriar e adaptar às próprias necessidades analíticas no futuro.

O título captura os dois nós conceituais centrais do trabalho de Bourdieu de uma vida inteira. O primeiro é a passagem da estrutura para a prática, interpretada como o que as pessoas fazem, pensam ou sentem em seu mundo cotidiano. Essa mudança reintroduziu o agente conhecedor, ativo e habilidoso (que é a principal tarefa do conceito de habitus, que Bourdieu recuperou e começou a aprimorar nos anos 1960), embora mantendo o modo de pensamento relacional - que é a força das abordagens estruturalistas em todas as ciências sociais, de Marx, Durkheim e Freud em diante. Isso faz de Bourdieu uma espécie de estruturalista antiestruturalista. $\mathrm{O}$ livro que assinala essa ruptura dialética com o estruturalismo é Esboço de uma teoria da prática (BOURDIEU, 2002a [1972]), que marca a saída oficial de Bourdieu da sombra de Claude Lévi-Strauss. Sobre a relação de Bourdieu com o papa do estruturalismo neo-saussuriano, recomendo a instigante monografia de Antoine Lentacker, La Science des institutions impures: Bourdieu critique de Lévi-Strauss (2010).

O segundo nó é o único conceito que, a meu ver, é epicentral e verdadeiramente original para Bourdieu: o poder simbólico, a capacidade de categorização consequencial, a capacidade de criar o mundo, preservá-lo ou modificá-lo, moldando e difundindo quadros simbólicos, instrumentos coletivos de construção cognitiva da realidade. Ele se ramifica de modo mais abrangente, multifacetado, e é mais poderoso do que os conceitos de habitus, capital e campo juntos e elevados ao quadrado (fico sempre intrigado, para dizer o mínimo, quando deparo com "visôes gerais" de Bourdieu que nem sequer mencionam a noção). Ele ancora a tríade cognição-reconhecimento-falta de reconhecimento que capta a visão bourdieusiana do agente social como um "animal simbólico”, para usar a linguagem de Ernst Cassirer, que é a principal inspiração por trás do pensamento de Bourdieu nessa frente - aqui, o livro-chave a considerar é o majestoso Ensaio sobre o homem: introdução a uma filosofia da cultura humana, de Cassirer (1994 [1944]). Trata-se, porém, de um agente materializado e incorporado que existe fundamentalmente aos olhos dos outros, mediante um "jogo de espelhos" recursivo em que as ficçóes sociais se tornam realidade na medida em que se baseiam em categorias compartilhadas e crenças comuns que fundamentam uma ação condizente. $\mathrm{O}$ capital simbólico também captura a noção de Bourdieu de que o poder nunca é tão eficiente (e perigoso) como quando se disfarça e é paradoxalmente ativado pelo subordinado, de modo que ele avança por meio de uma relação cognitiva de opaco consentimento para si mesmo, evitando assim o dispêndio de persuasão material. A violência simbólica é aquela força sem esforço que molda o mundo sem que o percebamos por intermédio da comunicação; ela ilude dominantes e dominados indistintamente, como em $A$ dominação masculina (BOURDIEU, 1999a [1998a]).

$\mathrm{O}$ poder simbólico é um conceito que Bourdieu elabora em todo o espectro de sua vida científica, de suas pesquisas de juventude sobre honra na Cabília e parentesco no Bearne até suas obras sobre arte, educação e sofrimento social, bem como suas incursóes posteriores em política e retorno à própria ciência. Ele está expresso de maneira mais compacta na pragmática sociológica de $O$ que falar quer dizer: a economia das trocas linguisticas (Idem, 1998b [1982a]) e nas Meditaçóes pascalianas (Idem, 2001a [1997]). Sua melhor ilustração é encontrada em seu curso Sobre o Estado (Idem, 2014 [2012]) como “poder 
simbólico supremo", "supremo fetiche" e "garantia de todos os fetiches". Entender essa noção [de poder simbólico] é uma jornada interminável, mas estimulante, e conhecê-la a fundo equivale a dar conta e conhecer a fundo a totalidade do trabalho de Bourdieu.

Com base nisso, sinto que o seminário foi concebido para criar as condiçóes sociais de produção de um habitus sociológico distinto. Lembro-me de suas instruçóes aos participantes no primeiro dia, quando apresentou a proposta triádica de "ler-escrever-discutir" constantemente, não apenas durante o seminário das 3 horas da tarde, mas também pelas memórias analíticas de cinco páginas que todo mundo tem para criar e compartilhar com todos os demais antes de cada reunião. Essas três atividades revelaram-se intrinsecamente ligadas ao longo do semestre e depois fundidas no dossiê preparado pelos participantes para o final do periodo. Podemos falar, então, da criação de um habitus sociológico e, em caso afirmativo, qual o papel da universidade, dos professores, dos alunos e dos cursos nesse processo?

Sua intuição está correta. Nesse seminário tentamos, individual e coletivamente, combater o viés escolástico inerente à situação acadêmica da sala de aula para transmitir uma disposição geradora para com a teoria como meio pragmático para a fabricação de objetos sociológicos. Bourdieu é um pensador paradoxal porque é visceral e epistemologicamente um teórico social antiteoricista - visceralmente porque pertence à sua classe e sua criação étnica foi em uma aldeia rural isolada do sudoeste da França, mundos afastados da experiência protegida da skholé, na qual os estudiosos se deleitam, e epistemologicamente por conta dos ensinamentos de seu mentor Georges Canguilhem, que enfatizava que a razão científica reside nas práticas históricas dos cientistas em ação; o texto essencial sobre isso é a sua enigmática, porém estimulante,
La formation du concept de réflexe au $17 \grave{e}$ et au 18 è siècle (CANGUILHEM; 1955). Isso é algo difícil de detectar, entender e absorver porque vai contra a corrente do que aprendemos na escola, que diz que os teóricos sociais são uma raça especial e superior e que as mentes fundadoras da disciplina são uma tropa dos assim chamados "teóricos". Somos ensinados a abordar os textos dos sociólogos clássicos - Marx, Durkheim, Weber, Simmel e Du Bois, entre outros - como escrituras sagradas a serem reverenciadas, e por isso tendemos a abordar Bourdieu desse modo. Esse é um erro categórico e representa um imenso obstáculo para entender seu trabalho. A maneira correta de abordar um texto de Bourdieu é como se ele fosse um guia de instruçóes para formular perguntas científicas inteligentes e fazer o difícil trabalho manual necessário para resolvê-las empiricamente.

Bourdieu insistia que não "fazia teoria". Ele constantemente nos adverte contra as seduçóes da dissertação conceitual pura e os perigos da "teorização", que tão facilmente se transformam em escolasticismo. Por volta de 1989, ele recusou um convite de Jeffrey Alexander, apóstolo do neofuncionalismo, para organizar uma espécie de "cúpula mundial" da teoria social com Jürgen Habermas, porque essa agenda simplesmente não fazia sentido para ele - sem falar dos participantes. Assim, nosso seminário se esforça para concentrar a atenção em como Bourdieu forja e usa conceitos, o que ele faz com eles e o que ele faz eles fazerem, em vez de como ele os define ou de quem ele os deriva. Conhecer as 13 - ou são 26? - diferentes definiçôes de habitus que se podem rapidamente extrair de textos que abrangem quase meio século diz muito pouco sobre quando, por que e como empregar a noção para adequar ao modo de pensar genético que ela encapsula. Para uma formulaçáo deste ponto, ver "Concise genealogy and anatomy of habitus" (WACQUANT, 2016). 
Essa abordagem gera uma inevitável tensão no eixo do seminário porque, para tirar proveito da leitura de Bourdieu, como acontece com todos os autores complexos e com múltiplas camadas, você precisa conhecer os textos - sua intenção e conteúdo, composição, planos de fundo, ressonâncias e implicaçóes mútuas. No caso de Bourdieu, isso é particularmente desafiador, primeiramente porque ele é um escritor muito autoconsciente e disciplinado que, em toda investigação, apela tacitamente aos resultados de uma miríade de outras pesquisas paralelas (sua sociologia da religião é o trampolim permanente e invisível para sua sociologia da arte; sua sociologia da ciência sustenta sua sociologia da política etc.). Em segundo lugar, porque os principais textos de Bourdieu sempre envolvem um diálogo subterrâneo com os filósofos que o moldaram antes de se converter à ciência social. $A$ distinção (BOURDIEU, 2007 [1979]) é uma revisão silenciosa, mas brutal, da terceira crítica do juízo de Kant, bem como de um envolvimento dissimulado com Hume, que ele leu com carinho em sua juventude durante uma turnê pela Inglaterra - Paul Guyer, em Knowledge, reason, and taste: Kant's Response to Hume (2008), demonstra que a filosofia de Kant, incluindo sua ética, estética e metafísica, surgiu de um embate frontal com Hume. As Meditaçóes pascalianas (BOURDIEU, 2001a [1997]) representam um aceno não apenas a Husserl (e às suas Meditaçôes cartesianas), mas, por meio dele, à ala não dualista do racionalismo do século XVII - especialmente o monismo de Espinosa e o pluralismo de Leibniz -, da qual Bourdieu se vê como uma extensão.

Por isso, você deve prestar muita atenção aos textos sem fetichizar as palavras do autor e praticar uma espécie de leitura reversa, retrocedendo, continuamente, dos resultados substantivos e argumentos propositivos em cena para o projeto de pesquisa e para as operaçóes que os sustentam, de modo a captar a maneira de pensar que os mantém juntos. Para ajudar a conseguir isso, lemos investigaçóes precoces e tardias sobre a mesma questáo (toda a obra de Bourdieu é informada por essa estratégia de "retorno e reformulaçáo") e comparamos escritos abstratos com experimentos sociológicos concretos. Por exemplo, para explicar a noção de reflexividade, lemos a elaboração específica de Bourdieu do racionalismo histórico como epistemologia de trabalho nas cem primeiras páginas de $A$ profissão de sociólogo (BOURDIEU; CHAMBOREDON; PASSERON, 1999 [1968]), com os testes práticos do olhar sociológico no primeiro capítulo do Homo academicus (BOURDIEU, 2011 [1984]), intitulado "Um livro para queimar". Começamos a mergulhar na reconstrução de Bourdieu da invenção histórica do olhar estético em As regras da arte (Idem, 1996 [1992]), com seu estudo-piloto de "O camponês e a fotografia" (BOURDIEU; BOURDIEU, 2006 [1965]) em sua aldeia natal no Bearne, que serviu como um balão de ensaio para fundamentar a crítica da falácia universalista da estética kantiana.

Embora seja paradoxal usar um formato escolástico para combater o escolasticismo, quando todos fazem sua parte e tratam o material com entusiasmo, o seminário torna-se uma locomotiva pedagógica que carrega seus próprios trilhos, resolvendo as dificuldades da mesma forma que faz com que elas surjam. Além das especificidades da pesquisa de Bourdieu, gostaria de ensinar uma atitude mais geral em relação ao trabalho sociológico que aprendi com ele, que é mais bem resumida na noção de vigilância epistemológica de Gaston Bachelard - ou "superego intelectual até ao terceiro grau", conforme exposto em seu livro O racionalismo aplicado (BACHELARD, 1977 [1949]): saber de onde vêm seus problemas, formular suas próprias questóes e formar construtos analíticos robustos, em vez de tomar emprestadas as noçôes frágeis e esponjosas do senso comum (incluindo o senso comum 
acadêmico), questionar metodicamente seus métodos e adotar uma postura proativa quando se trata da produção de dados. Observe que não digo "coleta" de dados, o que é um absurdo evidente: os dados são construidos fazendo-se uma pergunta rigorosa em um projeto empírico; um dado não existe como tal por si só, para ser "colhido" à maneira de uma estrela-do-mar, encalhada em uma praia. Nunca aceite um objeto pré-fabricado, esse é o primeiro mandamento que todo sociólogo deve ter em mente.

Já quanto ao papel das universidades, infelizmente elas se tornaram grandes obstáculos à produção e à transmissão de disposiçôes científicas, à medida que se reorganizam como fábricas de habilidades "baratas e cruéis", adaptadas à demanda de curto prazo do mercado, sob constante austeridade orçamentária. As universidades públicas, em particular, são uma lembrança do que costumavam ser há apenas duas décadas. Nós fazemos alguma pesquisa e ensinamos o que podemos apesar da universidade, e não graças a ela. Em um seminário, em todo caso, os alunos fazem o grosso do trabalho, individual ou coletivamente. Realizar um seminário é como reger uma orquestra amadora: eu gesticulo para dar o andamento, mas cabe aos participantes produzir a música sociológica.

\section{Existe o desafio adicional de administrar niveis} dispares de conhecimento e de expectativas dos participantes, incluindo acadêmicos e estudantes de doutorado como eu, vindos de vários paises estrangeiros, que têm visóes diferentes, se não opostas, de Bourdieu, moldadas pelas variadas apropriaçóes nacionais de seu trabalho.

$\mathrm{Na}$ verdade, o seminário atrai pesquisadores de todas as disciplinas e de todos os continentes que chegam até aqui com suas próprias imagens pré-fabricadas de Bourdieu, que, na maior parte dos casos, são seriamente truncadas: o Bourdieu "teórico da reproduçâa", quando seus três primeiros livros versavam sobre a transformaçáo cataclísmica de uma sociedade colonial em guerra; o Bourdieu que "ignora a agência”, quando o propósito do habitus é exatamente repatriar o agente inventivo para o centro da análise social; o Bourdieu que "náo teorizava as ligaçôes entre os campos", quando um de seus conceitos mais distintivos, o de campo do poder, é projetado especialmente para isso; ou o Bourdieu que "não enxerga a etnia", quando ele escreveu extensamente sobre as gradaçôes culturais de (des)honra e foi, ele mesmo, um "étnico" na sociedade francesa, e assim por diante. O Bourdieu turco não é o Bourdieu brasileiro, que não é o Bourdieu norueguês nem o Bourdieu francês: cada país desenvolveu sua própria versão seletiva, adequada à estrutura e à história de seu campo intelectual - de acordo com princípios enunciados por esse sociólogo em sua discussão de "As condiçóes sociais da circulação internacional de ideias" (Idem, 2002b [1990a]).

Bachelard nos ensina que o conhecimento científico procede não do preenchimento de um vazio, mas do rompimento com o "conhecimento espontâneo" que já existe, e isso não é diferente quando se trata de obras clássicas da sociologia, quando elas viajam através das fronteiras. As primeiras sessóes do seminário são suficientes para dissipar as fiç̧ôes de Bourdieu que, paradoxalmente, foram o motivo que atraiu as pessoas em primeiro lugar. Isso é divertido de fazer e feito com facilidade se adotamos para seu trabalho, tratado como fato social e científico, a perspectiva genética que Bourdieu nos exorta a lançar mão para qualquer realidade social.

Além de situações estereotipadas, também é preciso lidar com as emoçôes fortes, positivas ou negativas, que a obra de Bourdieu invariavelmente suscita, que se fixam nos objetos que examina, nos modelos que propóe ou na postura intelectual mais geral que estipula. Ele tem o dom de aprofundar seus leitores em suas 
análises, seja por analogia ou por homologia, e fazê-los sentir-se pessoalmente implicados neles. Sua sociologia é uma socioanálise, no sentido de que desvela o inconsciente social, alojado em corpos e instituiçóes, que governa a todos nós e promove o "retorno do reprimido". Isso é mais visível em $A$ miséria do mundo (BOURDIEU et al., 1997 [1993]) e na dissecação que Bourdieu faz dos três microcosmos sociais que o moldaram: 1) a sociedade da aldeia do Bearne, na qual cresceu, em $O$ baile dos celibatários (BOURDIEU, 2002c); 2) o sistema acadêmico por meio do qual despontou, no Homo academicus (Idem, 2011 [1984]); e 3) a instituição filosófica com a qual rompeu, em A ontologia política de Martin Heidegger (Idem, 1989a [1988]), que é uma forma de exorcizar o filósofo que ele poderia ter se tornado.

Esse retorno produz um efeito de revelação que pode trazer alegria e ser até mesmo libertador. Não raramente, no final de suas palestras públicas as pessoas se aproximavam de Bourdieu, agradecendo por ele ter rasgado o véu de ilusóes em que viviam envolvidas e que alteravam sua existência. Mas o efeito de revelação também pode ser penoso ou sufocante se você não estiver preparado para isso. Bourdieu faz as pessoas desabrocharem ou se contorcerem, gritarem ou se encolherem; ele raramente as deixa indiferentes. Seus argumentos aparentemente mais abstratos sempre carregam um de fabula narratur de Horácio, o que explica as reaçóes polarizadas que desencadeiam, tendendo à sedução ou à repulsa, com muito pouco entre esses extremos. A tarefa do seminário é fazer a transição dessa confusa "compreensão do coração" para uma compreensão racional do argumento, dos conceitos que ele envolve e dos princípios epistemológicos que o sustentam.

Bourdieu é especialmente ameaçador para estudiosos que têm estruturas mentais rígidas e concebem a investigação social como a aplicação reflexa de fórmulas mecânicas prescritas por um credo teórico abrangente - e, nessa frente, os últimos marxistas competem com os parsonianos sobreviventes. Um ilustre colega de Berkeley que fez meu seminário - e queria fazer uma segunda vez, mas não permiti - viajou pelo mundo proferindo uma palestra com o título furiosamente freudiano: "Quem tem medo de Pierre Bourdieu?”. Para compreender e depois implementar seu modo de raciocínio, você precisa renunciar à sacralização dos pensadores e tornar-se uma espécie de ginasta intelectual. Você deve aprender a se dobrar e se contorcer em posiçóes teóricas incomuns, se não perigosas: levar Marcel Mauss a Max Weber, cruzar o corpo de Merleau-Ponty com o "homem neuronal" de Jean-Pierre Changeux, fazer com que Roman Jakobson e John Austin entrem na fila no mesmo barco linguístico, mergulhar em estatísticas matemáticas sérias e ainda escutar as ideias sociais aninhadas nas inovaçóes literárias de uma Virginia Woolf ou de um Thomas Bernhard. Para ilustrar, contraponha a dissecação quantitativa de Bourdieu de "Uma revolução conservadora na edição" (Idem, 1999b) à leitura autorreflexiva de Emily Dickinson, na qual ele revela William Faulkner como espécie de etnometodólogo literário em As regras da arte, (Idem, 1996 [1992]). Bourdieu nunca se inibe a tomar emprestadas noçóes e proposiçôes de tradiçôes teóricas dispersas, se não opostas, mas há uma razão para a ousadia: seu ecletismo teórico assentado em princípios é limitado por seu compromisso rígido com o que chamo de "os três Rs" de Bourdieu - uma epistemologia racionalista, uma ontologia relacional e uma metodologia reflexiva, que continuamente se questiona no próprio movimento em que é empregada.

Depois de ter lidado com imagens e emoçóes, você ainda tem que resolver a questão da linguagem bourdieusiana. Aqui, a primeira coisa a fazer é mostrar que o idioleto conceitual e seu estilo em espiral são empregados deliberadamente para impedir a interferência 
de noçôes populares e do raciocínio do senso comum na argumentação analítica. A segunda é se prevenir contra as seduçôes da fala bourdieusiana. Hoje em dia, os periódicos das ciências sociais e humanas estão desencadeando um tsunami de pesquisas invocando Bourdieu, mas a grande maioria dessas publicaçôes limita-se simplesmente a sobrepor um fino verniz de uma retórica que soa como de Bourdieu sobre projetos e resultados de pesquisa que náo têm nenhuma conexão com sua sociologia.

Apresento aqui um teste simples para verificar isso: pegue uma caneta e risque todas as mençôes a "habitus, capital e campo": se nada for perdido ao excluí-los, isso significa que nada foi ganho ao listá-los, a não ser participar do modismo intelectual do momento. A contrario, quando os conceitos e princípios analíticos de Bourdieu guiam operaçóes concretas de pesquisa, você está imediatamente em condição de articular novas questôes e pintar uma nova paisagem empírica, como faz Tom Medvez (2012) em seu modelo de investigação da ascensão do Think tanks in América, que perpassa a tela de estudos de elite e políticas para compreender a ambiguidade intrínseca desse animal organizacional e diagnosticar seu papel turvo no campo do poder dos Estados Unidos.

Indo contra as visöes convencionais de Bourdieu, ancoradas na tríade "babitus, capital e campo", você nos coloca diante da díade "espaço social e poder simbólico", vistos como os conceitos básicos que organizam o trabalho dele. Você argumenta que a mudança da tríade para a díade não apenas esclarece erros comuns, como também lança luz sobre a lógica interna do projeto de Bourdieu. Você pode explicar o que está envolvido nessa mudança?

Ao longo de três anos, preparei uma nova edição ampliada, corrigida e atualizada de $U m$ convite à sociologia reflexiva (BOURDIEU;
WACQUANT, 2005 [1992]), cobrindo a última e mais prolífica década da produção de Bourdieu. O estímulo para isso foi a necessidade de retraduzir o livro para o francês em sua totalidade, o que fiz com a colaboraçáo especializada de Etienne Ollion: essa nova versão não existiria se não fosse sua contribuição. Para isso, li enorme quantidade de textos dispersos, obscuros e aparentemente menores de Bourdieu, muitos deles nem sequer listados em sua bibliografia oficial, o que acabou por oferecer novas perspectivas sobre suas intençóes e sobre a arquitetura interna de seu trabalho. Também escrevi um ensaio extenso estabelecendo dois itinerários de leitura complementares através da totalidade de seu corpus, num total de mais de 700 itens. $\mathrm{O}$ primeiro é um caminho genético, que refaz o desenvolvimento de sua estrutura em cinco etapas; o segundo é um caminho analitico, que esclarece a elaboração e o propósito dos sete conceitos-chave (habitus, capital, campo, espaço social, poder simbólico, doxa e reflexividade) que ancoram o modo distintivo do pensamento de Bourdieu.

$\mathrm{O}$ fato de eu ter igualmente vasculhado as transcriçôes de seus seminários e cursos no Collège de France e as milhares de páginas de correspondência que trocamos para escrever o Convite, com a vantagem da retrospectiva analítica, transformou totalmente minha compreensão de Bourdieu. Era como atravessar uma tela que eu sequer sabia que estava lá, levando-me a descobrir novas balizas para navegar pelo oceano de seu trabalho. $\mathrm{O}$ molde fundamentalmente antiteoricista do pensamento de Bourdieu me assaltou como nunca o fizera antes; a influência decisiva de Cassirer tornou-se evidente (do lado da epistemologia, ele era o equivalente estrutural alemão de Bachelard para a escola de Marburg). Também emergiu o uso metódico da sua aldeia do Bearne como uma base experimental para testar, em miniatura, grandes empreendimentos de pesquisa e muitas outras características 
inovadoras, como a composição multiescalar do campo do poder e a teoria tácita de revolucionários simbólicos que permeiam seus ensaios dispersos sobre Flaubert, Heidegger, Baudelaire, Beethoven e Manet.

Porém, o mais importante é que se tornou nítido para mim que o espaço social é a categoria-mãe, o conceito genérico do qual deriva logicamente o conceito específico de campo, como um espaço social especializado que surge quando um domínio de ação e autoridade se torna suficientemente demarcado, autonomizado e monopolizado. Perceber que espaço social (e não o campo) é o construto geral que "enfrenta" os conceitos de habitus e de capital para gerar a prática elimina dificuldades recorrentes e dissolve miríades de falsos problemas. Primeiro, isso nos lembra que os campos são animais históricos relativamente raros, que existem apenas em certos domínios de atividade e apenas em formaçóes sociais avançadas que passaram por uma diferenciação suficiente - não é à toa que Bourdieu continua invocando a designação durkheimiana de sociedades diferenciadas em vez de sociedades modernas, capitalistas ou pós-industriais.

Craig Calhoun (1993) destacou a estreita historicidade dos campos em sua arguta contribuição "Bourdieu: critical perspectives", mas ele a viu como uma tensão não resolvida presente na teoria da prática em lugar de detectar uma falta de especificação da relação entre campo e espaço social. Por exemplo, não há campos na Cabília colonial porque as formas de capital não são desenredadas e classificadas em faixas institucionais distintas. Assim, Bourdieu náo usa o termo quando revisita seu trabalho de campo de juventude em $O$ senso prático (publicado em 1980, uma década depois de ter produzido sua primeira robusta elaboraçáo de campo com o artigo "Gênese e estrutura do campo religioso" (BOURDIEU, 1974 [1971]), que fornece um modelo para todos os outros campos.
A ação social se desenrola, em sua maior parte, em espaços sociais que são apenas isso, espaços sociais, isto é, distribuiçóes multidimensionais de propriedades (capitais) socialmente eficientes, estipulando um conjunto de posiçóes padronizadas a partir das quais se pode inteligivelmente prever estratégias. Porém, eles não são campos porque não têm fronteiras institucionalizadas, nem barreiras para a entrada e nem especialistas que elaborem uma fonte distinta de autoridade e de sociodiceia. Essa revisão permite-nos evitar a multiplicação cômica de campos e formas de capital ad infinitum - dificilmente passa-se um mês sem que algum estudioso proponha uma nova espécie! Assim, não há "campo sexual" (com o devido respeito a GREEN, 2013; ILLOUZ, 2012) e não há "campo racial" desculpem-me Matthew Desmond e Mustafa Emirbayer (2015) - pela simples razão de que nem sexo nem raça, como etnia negada, são monopolizados por um nexo de instituiçóes e agentes distintos que os elaboram para o consumo de outros, como os padres fazem para os leigos ou os políticos para os eleitores. De fato, sua importância sociológica reside precisamente no fato de que eles atravessam os microcosmos e modelam o espaço social em geral por meio da formação de habitus: são princípios de visão e divisão sociais que não foram encurralados nos campos. De forma mais ampla, a promoção do espaço social como categoria-âncora coincide com a reformulação de Bourdieu da questão da formação de grupos pós-Distinção (que ele considerou grosseira e obsoleta nessa frente), que elimina a presunção da existência de classes para pavimentar o caminho para uma ontologia radicalmente historicista de coletivos sociais - esse argumento é feito na íntegra no meu artigo "Symbolic power and group-making” (WACQUANT, 2013), que se aplica a todas as formas de coletivos étnicos, nacionais, religiosos, sexuais, etc. 
Parte da confusão em torno da relação entre campo e espaço social foi semeada pelo próprio Bourdieu de duas maneiras. Primeiro, ele desenvolveu a noção mais estreita de campo no período de 1968 a 1977, antes de ter concebido e elaborado completamente a categoria mais ampla de espaço social, no período que se estende de 1975 a 1985 e em diante. Mas isso não é surpreendente, uma vez que o sociólogo aperfeiçoou todos os seus conceitos para fins de investigaçôes empíricas específicas, indo de projeto de pesquisa em projeto de pesquisa, e não como parte de uma grandiosa metavisão parsoniana de um conjunto preconcebido de categorias analíticas. Em segundo lugar, Bourdieu teve que descobrir, aprender e adaptar as técnicas de análise de correspondência múltipla de Jean-Paul Benzécri para operacionalizar a noção de espaço social e daí operá-la conceitualmente - Lebaron e Le Roux (2015) mostram isso acidentalmente em La méthodologie de Pierre Bourdieu en action. Em terceiro, muitas vezes o próprio Bourdieu é desleixado quando usa os dois termos, mesmo depois de ter articulado a noção de espaço social: às vezes refere-se a campo social ou à família como campo e a várias configuraçôes que misturam espaço social simples com a interseção de vários campos como campos, o que eles não são. Stricto sensu, pode-se argumentar também que o assim chamado campo do poder não é, na verdade, um campo (não é o locus de concentração e distribuição de uma espécie distintiva de capital, não tem um nomos específico, não secreta um conjunto de construçôes cognitivas distintas etc.), mas um metacampo enquanto uma modalidade de espaço social de múltiplas camadas.

Já no que concerne à tríade conceitual "habitus, capital e campo", torna-se fácil mostrar que ela oferece, na melhor das hipóteses, uma condensação incoerente e incompleta do pensamento de Bourdieu (náo obstante o uso ocasional que ele próprio lhe confere para fins pedagógicos): capital e campo são redundantes, pois um campo não é nada além de um espaço de concentraçáo do capital; habitus em si é capital incorporado e, de outro ângulo, pode ser entendido como somatização de categorias cognitivas e catéticas, isto é, como a inscrição de poder simbólico sobre o organismo socializado. Se você levar a cabo o equivalente semântico da análise do menor espaço a la Guttman e Lingoes na estrutura de Bourdieu, vai descobrir que o duo espaço social e poder simbólico é suficiente para regenerar todos os outros conceitos que ele usa e daí capturar todas as formas de fenômenos. Sua articulação constitui o núcleo conceitual mais parcimonioso e irredutível de sua teoria da prática. É por isso que esse será o título do próximo "Acampamento Bourdieu" em Berkeley.

Você é um dos editores do último livro de Bourdieu (2014 [2012]), Sobre o Estado. No colóquio especial organizado pelo Departamento de Sociologia de Berkeley para marcar o lançamento da versão em inglês dessa obra, em março de 2015, você estabeleceu conexóes entre este ciclo de palestras e algumas obras de referência de Marx, Durkheim e Weber. Você pode nos dizer o que torna esse livro tão especial?

Em primeiro lugar, uma correção: eu náo fui um dos editores do curso do Collège de France sobre o Estado. O editor-chefe foi o último doutorando de Bourdieu, Franck Poupeau, que foi convidado por Berkeley para lançar o colóquio que você mencionou precisamente por ter liderado a equipe de associados sêniores de Bourdieu encarregados dessa espinhosa tarefa. Passei cinco meses vasculhando dia e noite as mil páginas da penúltima versão, linha por linha. Recomendei que fossem feitas revisōes profundas do início ao fim (cortes, reescritas, esclarecimentos terminológicos, notas adicionais, referências 
etc.), que foram, na sua maioria, incorporadas ao texto final. A equipe de Paris tendia a ficar mais perto da palavra falada, em uma atitude de deferência editorial ao mestre. Tenho a vantagem de ter estabelecido uma relação com Bourdieu e de ter tido a experiência de escrever com Bourdieu, diferentemente dos seus antigos alunos. Isso me deu uma espécie de impudência editorial que eles simplesmente não poderiam ter, por boas razóes sociológicas, e que forneceu o equilíbrio necessário no final.

Por estranho que pareça, mantenho uma conexão mais próxima com o início desse curso. Na primavera de 1986, Bourdieu fez uma escala em Chicago, onde eu estava começando meu doutorado vindo de San Diego, local em que estive a convite do seu amigo Aaron Cicourel, e a caminho de Princeton, onde participaria das Gauss Lectures in Criticism. Eu tinha acabado, naquele momento, de revisar uma exposição crítica de seu trabalho, comparando sua "Liçóes da aula" (Idem, 1988 [1982b]), que inaugurara sua cadeira no Collège de France, com uma soberba monografia de um de seus alunos de doutorado, Sylvain Maresca (1983), sobre como os "sindicalistas rurais" redesenharam a fronteira do campesinato no pós-guerra e transformaram materialmente o grupo por meio do trabalho simbólico realizado em conjunto com os gestores de políticas públicas. Foi uma espécie de exercício paradigmático e exemplar (no sentido de Thomas Kuhn) que Bourdieu me encorajara a escrever alguns anos antes, enquanto eu morava e trabalhava na Nova Caledônia - por isso o artigo acabou sendo publicado em uma revista acadêmica australiana! Ele o leu atentamente e ficou irritado com as críticas que havia desenvolvido no final, a pedido de meus professores de Chicago, John Comaroff e James Coleman, especialmente meu foco em seu "ponto cego flagrante sobre o Estado”. Minha terceira crítica dizia assim:
Deve ser expressa a preocupação com a desconsideração teórica para com o papel do Estado que caracteriza a concepção de Bourdieu do espaço social. O fato de ele náo ter sido inserido nos sumários de seus três livros mais importantes (Bourdieu, 1972, 1979a, 1980a) indica que o Estado está visivelmente ausente do quadro de Bourdieu. Esforços recentes para remediar essa falha e colocar o Estado no centro da teoria da violência simbólica levaram à sua (re) definição como "a agência que possui o poder da nomeação legítima, ou seja, o poder que permite a imposição oficial da visão legítima do mundo social" (Bourdieu, 1984 [1979]: 118). Definir um conceito, no entanto, não é prova de seu potencial analítico. Resta mostrar o quanto Bourdieu é capaz de extrair de uma definição tão restrita, que pode eventualmente aprisioná-lo exatamente no tipo de posiçẫo subjetivista que ele rejeita: a redução das relações de dominação às relações de significação. O teórico social francês terá que ir muito além das questốes de nomeação e classificação se, como acredito, seu esquema é contribuir decisivamente para a análise de classe. Pois o Estado faz consideravelmente mais do que atribuir títulos e impor taxonomias: também administra uma teia gigantesca de pontes entre campos (legal, político-econômico, social, cultural) cujos limites, barreiras à entrada e limites específicos podem ser facilmente alterados pela força, se necessário, afetando em muito a estruturação de classes. Surge, então, a questão de saber se o poder do Estado constitui uma espécie de capital sui generis e as instituições estatais representam um campo essencialmente diferente de outros campos. (WACQUANT, 1987, p. 79-80)

Em Chicago, Bourdieu descartou a crítica como simples, insistindo que o Estado era uma entidade demasiadamente complexa e antiga para se atacar de frente de qualquer maneira. O Estado também foi um assunto na moda naquela época, com o ostentatório lançamento no ano anterior do volume coletivo Bringing the State back in, organizado em nome do Social Science Research Council por Peter Evans, Dietrich Rueschemeyer e Theda Skocpol (1985), que importou para os Estados Unidos o fascínio teórico para com o Estado que havia consumido os neomarxistas europeus da década de 1970, como Nicos Poulantzas, Claus Offe e Perry Anderson - os 
althusserianos representaram um desvio total para Bourdieu! Mas dias depois de ele ter deixado a cidade, recebi um telefonema surpresa de Princeton, no qual admitiu categoricamente: "Bem, você está certo, vou dedicar meu próximo curso no Collège ao Estado para responder à sua crítica". Depois de três veróes de intensa leitura, e tendo encontrado um gancho empírico no qual pendurar sua pesquisa, ou seja, o enquadramento político da produção e da aquisição de unidades residenciais isoladas - isso rendeu um relatório para a Caisse des Dépots et Consignation, a agência estatal que financia a construção habitacional na França e, em seguida, um número duplo de Actes de la recherche en sciences sociales (BOURDIEU et al., 1990), que posteriormente se transformou em The social structures of the Economy (Idem, 2001b [2000]) -, Bourdieu dedicou-se a enfrentar o Estado diretamente e nunca mais deixou de fazê-lo.

Esse movimento foi fortalecido pela finalizaçáo do seu livro sobre o papel das escolas de elite na reprodução do campo do poder, a que Bourdieu acrescentou extensa discussão final em "Pouvoir d'État et pouvoir sur l'État", cujo título ele mudou no último minuto, de La noblesse d'École para La noblesse d'État (Idem, 1989b). Essa mudança deixava claro que a educação é o principal veículo pelo qual a inculcação de categorias estatais de pensamento opera (embora em seu trabalho sobre educação, datado da década de 1960, Bourdieu tenha curiosamente oposto a escola ao Estado) e estipulava que o Estado é, ao mesmo tempo, o produto, o local, o alvo e o árbitro das lutas para conformar a realidade. A orientação relativa ao Estado também foi necessária devido ao foco cada vez mais direcionado de Bourdieu ao poder simbólico durante toda a década, o que logicamente o estimulou a enfrentar o grande "alquimista simbólico" da era moderna. Você pode detectar isso, por exemplo, no capítulo histórico sobre a unificação linguística da França a mando das autoridades políticas, que abre O que falar quer dizer (Idem, 1998b [1982a], p. 23), e que demonstra que "a produçáo e a reprodução da linguagem legítima" operam em conjunto com a construção do Estado central, primeiro pela realeza absolutista e depois pela burguesia republicana, cujo poder depende cada vez mais da transmissão do capital cultural validado pelo Estado, isto é, das credenciais educacionais.

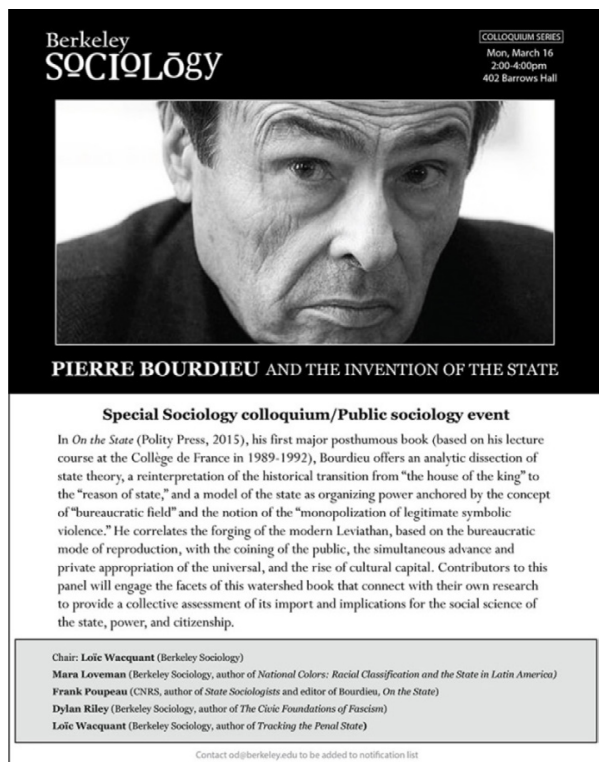

Tudo isso para dizer que Bourdieu estava destinado a atingir o Leviatá mais cedo do que supunha. Contudo, é engraçado ler agora a crítica imatura que fiz em 1986, formulada de forma desajeitada, e perceber que ela estava no centro da questão e que desempenhou um pequeno papel na aceleração da "saída" de Bourdieu para o Estado. Mais tarde, durante aqueles longos verôes de intensa leitura em sua aldeia do Bearne, ele reclamava, brincando: "Você está ferrado, estou trabalhando duro pra caramba, mastigando teorias do Estado 24 horas por tua causa, e isso não tem graça”. Até o curso, o Estado revelou-se espécie de presença ausente no centro de seu trabalho, desde a recapitulaçáo da espoliação 
da terra na construção da sociedade colonial em Sociologie de l'Algérie (Idem, 1958) até a sociologia da educação (BOURDIEU, 1989b; BOURDIEU; PASSERON, 2014 [1964], 1982 [1970]) e as investigaçóes do início dos anos 1990 sobre o sofrimento social causado pela ampliação do domínio do mercado, chegando ao clímax no ressurgimento do envolvimento de Bourdieu com o debate cívico.

O que faz de Sobre o Estado um texto verdadeiramente único, o livro mais extraordinário de ciência social que eu já li? Ele combina o frescor e a ousadia de Grundrisse: manuscritos econômicos de 1857-1858, de Marx (um arrojado edifício provisório de princípios fundamentais a ser refinado), a profundidade e o vigor das Formas elementares de vida religiosa, de Durkheim (o Estado passa a ser uma gigantesca "máquina de classificação" e "uma parte da Igreja voltou-se contra si mesma" (BOURDIEU, 2014 [2012], p. 262-265, 526): há algo mais durkheimiano do que isso?), e o escopo e a ambição da sociologia da religiáo de Weber (que abarca oito séculos e três continentes para construir um tipo ideal). E a essas características deve ser adicionado um questionamento incansável, sagaz e ansioso da própria ambição e do ato de interrogação sociológico, que é típico de Bourdieu. Ao longo do curso, o autor de $A$ distinção oferece uma dissecação analítica de teorias do Estado (algo que ele não fez para nenhum outro tema), uma ousada reinterpretação da transição histórica da "casa do rei" para a "razão de Estado" e um modelo inovador do Estado como poder organizador, ancorado no conceito de campo burocrático, e na noção de "monopólio da violência simbólica legítima".
Ele correlaciona a formação do moderno Leviatã, baseado no modo burocrático de reprodução, com a criação do público e o avanço simultâneo da apropriação privada do universal e da ascensão do capital cultural. Essa é uma investigação com escopo, profundidade e alcance clássicos.

$\mathrm{O}$ livro, que deveria ter sido intitulado "A invenção do Estado" (a expressão é repetida mais de 30 vezes nas palestras e na seção de encerramento de $A$ nobreza do Estado, que remixa um trecho de um rascunho de aula do Collège, chamado de "Os togados e a invenção do Estado"), não é evidentemente o que Bourdieu teria publicado se tivesse vivido para escrevê-lo. Pois, ao contrário do que afirmam os editores do volume no posfácio, ele pretendia escrever um tomo sobre o Estado. O que o impediu de fazê-lo, por volta de 1995, é que ele não conseguiu descobrir como localizá-lo no estudo mais amplo de vários volumes que estava preparando na teoria geral dos campos, provisoriamente intitulada "Microcosmos". Mas podemos nos alegrar porque náo há muito mais a aprender com o rascunho falado do livro que náo foi. É inacabado, cru, cheio de bordas irregulares, formulaçôes inquisitivas, pistas luminosas, elipses analíticas e questóes não resolvidas, e transborda de candura angustiada sobre as exigências epistêmicas e as dificuldades práticas do ofício sociológico. Não é um produto acabado, um opus operatum sobre o Estado, mas antes o movimento de sua fabricação paralisada, o modus operandi vivo de Bourdieu, construindo meticulosamente aquele que foi, talvez, seu objeto mais desafiador. E essa é, eu sugiro, a melhor maneira de capturar seu motor sociológico em perpétuo movimento.

\section{Referências}

BACHELARD, G. Le rationalisme appliqué. Paris: Presses Universitaires de France, 1949.

O racionalismo aplicado. Rio de Janeiro: Zahar, 1977.

BOURDIEU, P. Sociologie de l'Algérie. Paris: Presses Universitaires de France, 1958. 
. Genèse et structure du champ religieux. Revue Française de Sociologie, Paris, n. XII, p. 295-334, 1971.

. "Gênese e Estrutura do Campo Religioso". In: BOURDIEU, P. A Economia das Trocas Simbólicas. Trad. Sergio Miceli. São Paulo: Ática, 1974.

Esquisse d'une théorie de la pratique, précédée de Trois essais d'ethnologie kabyle. Genève: Librairie Droz, 1972.

La distinction une critique sociale du jugement. Paris: Les Éditions de Minuit, 1979.

Le sens pratique. Paris: Les Éditions de Minuit, 1980.

Ce que parler veut dire: l'économie des échanges linguistiques. Paris: Fayard, 1982a.

Leçon sur la leçon. Paris: Minuit, 1982b.

Liçōes da Aula. São Paulo: Ática, 1988.

Homo academicus. Paris: Les Éditions de Minuit, 1984.

. L'ontologie politique de Martin Heidegger. Paris: Les Éditions de Minuit, 1988.

A ontologia politica de Martin Heidegger. Campinas: Papirus, 1989a.

La noblesse d'État: grandes écoles et esprit de corps. Paris: Les Éditions de Minuit, $1989 \mathrm{~b}$.

Les conditions sociales de la circulation internationale des idées. Actes de la recherche en sciences sociales, Paris, v. 145 , n. 5 , p. $3-8,1990$ a.

. Coisas ditas. São Paulo, Brasiliense, 1990b.

Les règles de l'art: genèse et structure du champ littéraire. Paris: Seuil, 1992.

- As regras da arte: gênese e estrutura do campo literário. Tradução Maria Lúcia Machado. São Paulo: Companhia das Letras, 1996.

Méditations pascaliennes. Paris: Seuil, 1997.

La domination masculine. Paris: Seuil, 1998a.

O que falar quer dizer: a economia das trocas linguísticas. Tradução de Vanda Anastácio. São Paulo: Difel, 1998b.

A dominação masculina. Rio de Janeiro: Bertrand Brasil, 1999a.

. Une révolution conservatrice dans l'édition. Actes de la recherche en sciences sociales, Paris, n. 126-127, p. 2-28, 1999 b. 
Les structures sociales de l'économie. Paris: Seuil, 2000.

. Meditaçóes pascalianas. Traduçáo Sergio Miceli. Rio de Janeiro: Bertrand Brasil, 2001a.

As estruturas sociais da economia. Lisboa: Instituto Piaget, 2001b.

Esboço de uma teoria da prática, precedido de Três estudos de etnologia cabila. Oeiras: Celtga, 2002a.

. As condiçốes sociais da circulação internacional das ideias. Traduçấo Fernanda Abreu. Enfoques, Rio de Janeiro, v. 1, n. 1, p. XV-117, 2002b.

. Le bal des célibataires: crise de la société paysanne en Béarn. Paris: Seuil, 2002c.

. A distinção: crítica social do julgamento. Traduçấo Daniela Kern e Guilherme J. F. Teixeira. São Paulo: Edusp; Porto Alegre: Zouk, 2007.

Homo academicus. Tradução Ione Ribeiro Valle e Nilton Valle. Revisão técnica Maria Tereza de Queiroz Piacentini. Florianópolis: Ed. da UFSC, 2011.

. Sur l'État: cours au Collège de France (1989-1992). Paris: Seuil, 2012.

. Sobre o Estado: cursos no Collège de France (1989-92). Tradução Rosa Freire d'Aguiar. São Paulo: Companhia das Letras, 2014.

BOURDIEU, P.; BOURDIEU, M.-C. Le paysan et la photographie. Revue Française de Sociologie, Paris, v. VI, p. 164-174, 1965.

O camponês e a fotografia. Tradução Helena Pinto e José Madureira Pinto. Revista de Sociologia e Política, Curitiba, n. 26, p. 31-39, jun. 2006.

BOURDIEU, P.; CHAMBOREDON, J.-C.; PASSERON, J.-C. Le métier de sociologue: préalables épistémologiques. Paris: Mouton de Gruyter, 1968.

. A profissão de sociólogo: preliminares epistemológicas. Tradução Guilherme João de Freitas Vale. Petrópolis: Vozes, 1999.

BOURDIEU, P.; PASSERON, J.-C. Les héritiers: les étudiants et la culture. Paris: Les Éditions de Minuit, 1964.

La reproduction: éléments d'une théorie du système d'enseignement. Paris: Les Éditions de Minuit, 1970.

. Reprodução: elementos para uma teoria do sistema de ensino. 2. ed. Tradução Reynaldo Bairão. Rio de Janeiro: Francisco Alves, 1982.

Os herdeiros: os estudantes e a cultura. Florianópolis: Editora da UFSC, 2014. 
BOURDIEU, P.; WACQUANT, L. An invitation to reflexive sociology. Chicago: University of Chicago Press; Cambridge: Polity Press, 1992. Um convite à sociologia reflexiva. Rio de Janeiro: Relume-Dumará, 2005.

BOURDIEU, P. et al. L'économie de la maison. Actes de la recherche en sciences sociales, Paris, n. 81-82, mars 1990. Número temático. La misère du monde. Paris: Seuil, 1993. A miséria do mundo. Petrópolis: Vozes, 1997.

CALHOUN, C. Habitus, field, and capital: the question of historical specificity. In: CALHOUN, C.; LIPUMA, E.; POSTONE, M. (Orgs.). Bourdieu: critical perspectives. Chicago: University of Chicago Press, 1993. p. 61-88.

CANGUILHEM, G. La formation du concept de réflexe aux 17e et 18e siècles. Paris: Vrin, 1955.

CASSIRER, E. An essay on man: an introduction to a philosophy of human culture. New Haven: Yale University Press, 1944. Ensaio sobre o homem: introdução a uma filosofia da cultura humana. São Paulo: Martins Fontes, 1994.

DESMOND, M.; EMIRBAYER, M. The racial order. Chicago: University of Chicago Press, 2015.

EVANS, P. B.; RUESCHEMEYER, D.; SKOCPOL, T. (Orgs.). Bringing the State back in. Cambridge: Cambridge University Press, 1985.

GREEN, A. I. Sexual fields: toward a sociology of collective sexual life. Chicago: University of Chicago Press, 2013.

GUYER, P. Knowledge, reason, and taste: Kant's response to Hume. Princeton: Princeton University Press, 2008.

ILLOUZ, E. Why love hurts: a sociological explanation. Cambridge: Polity Press, 2012.

LEBARON, F.; LE ROUX, B. (Orgs.). La méthodologie de Pierre Bourdieu en action: espace culturel, espace social et analyse des données. Paris: Dunod, 2015.

LENTACKER, A. La science des institutions impures: Bourdieu critique de Lévi-Strauss. Paris: Raison d'Agir, 2010.

MARESCA, S. Les dirigeants paysans. Paris: Minuit, 1983.

MEDVEZ, T. Think tanks in America. Chicago: University of Chicago Press, 2012.

WACQUANT, L. Symbolic violence and the making of the French agriculturalist: an enquiry into Pierre Bourdieu's sociology. The Australian and New Zealand Journal of Sociology, Melbourne, n. 23, v. 1, p. 65-88, 1987. 
Symbolic power and group-making: on Pierre Bourdieu's reframing of class. Journal of Classical Sociology, Thousand Oaks, v. 13, n. p. 274-291, 2013.

. A concise genealogy and anatomy of habitus. The Sociological Review, Thousand Oaks, v. 64, n. 1, p. 64-72, 2016.

\section{Resumo}

\section{Prática e poder simbólico em Bourdieu: a visão de Berkeley}

Entre 2014 e 2015, Aksu Akçaoğlu foi professor visitante no Departamento de Sociologia da Universidade da Califórnia, em Berkeley, no qual trabalhou com Loïc Wacquant em sua pesquisa sobre "o habitus conservador" na Turquia contemporânea - com o apoio do Conselho de Pesquisa Científica e Tecnológica da Turquia (TÜBİTAK). Nesse diálogo, ele convida Wacquant a explicar a filosofia e a pedagogia de seu célebre seminário de Berkeley sobre Pierre Bourdieu, o que oferece uma oportunidade para revisitar os principais nós conceituais no trabalho de Bourdieu e destacar seu molde antiteoricista, bem como as influências de Bachelard e de Cassirer, esclarecer as relaçóes entre espaço social, campo e poder simbólico e alertar contra as seduçôes da "fala bourdieusiana".

Palavras-chave: Bourdieu; Prática; Espaço Social; Poder Simbólico; Antiteoricismo; Vigilância Epistemológica; Estado como Fetiche Supremo; Pedagogia da Pesquisa.

\section{Abstract}

Practice and symbolic power in Bourdieu: the view from Berkeley

In 2014-2015, Aksu Akçaoğlu was a visiting scholar in the Department of Sociology at the University of California, Berkeley, where he had come to work with Loïc Wacquant on his research on "the conservative habitus" in contemporary Turkey (with the support of the TÜBİTAK Science Program). In this dialogue, he invites Wacquant to explicate the philosophy and pedagogy of his celebrated Berkeley seminar on Pierre Bourdieu. This provides an opportunity to revisit key conceptual nodes in Bourdieu's work, to spotlight its anti-theoreticist cast as well as the influences of Bachelard and Cassirer; to clarify the relationships between social space, field, and symbolic power; and to warn against the seductions of "speaking Bourdieuese."

Keywords: Bourdieu; Practice; Social Space; Symbolic Power; Anti-Theoreticism; Epistemological Vigilance; The State as Supreme Fetish; Research Pedagogy.

\section{Résumé}

\section{Pratique et pouvoir symbolique chez Pierre Bourdieu: le point de vue de Berkeley}

Entre 2014 et 2015, Aksu Akçaoğlu a été chercheur visitant au Département de Sociologie de l'Université de Californie, Berkeley, où il est venu travailler avec Loïc Wacquant sur sa recherche sur "l'habitus conservateur" en Turquie contemporaine (avec l'appui du TÜBİTAK Science Program). Dans ce dialogue, il invite Wacquant à expliquer la philosophie et la pédagogie de son réputé séminaire de Berkeley sur Pierre Bourdieu. Le dialogue fournit une occasion pour revisiter les nœuds conceptuels clés du travail de Bourdieu et signale sa perspective anti-theoriciste, ainsi que les influences de Bachelard et Cassirer. Outre la clarification des relations entre espace social, champ et pouvoir symbolique, le dialogue met en garde contre les séductions du " parler Bourdieusien ».

Mots-clés: Bourdieu; Pratique; Espace Social; Pouvoir Symbolique; Anti-Théoricisme; Vigilance Épistémologique; L'État comme Fétichisme Suprême; Pédagogie de la Recherche. 